Original Research Paper

\title{
A Multifactor Authentication Framework for the National Health Insurance Scheme in Ghana using Machine Learning
}

\author{
${ }^{1}$ Isaac Kofi Nti, ${ }^{2}$ Adebayo Felix Adakoya and ${ }^{2}$ Owusu Nyarko-Boateng \\ ${ }^{1}$ Department of Computer Science, Sunyani Technical University, Sunyani Ghana \\ ${ }^{2}$ Department of Computer Science and Informatics, University of Energy and Natural Resource, Sunyani-Fiapre, Ghana
}

\author{
Article history \\ Received: 11-07-2020 \\ Revised: 23-08-2020 \\ Accepted: 29-10-2020 \\ Corresponding Author: \\ Isaac Kofi Nti \\ Department of Computer \\ Science, Sunyani Technical \\ University, Sunyani Ghana \\ Email: ntious1@gmail.com
}

\begin{abstract}
The creation of the National Health Insurance Scheme (NHIS) in 2005 to replace the traditional "cash and carry" healthcare financial model, was anticipated to offer a safe, reliable, affordable and national coverage healthcare system for the Ghanaian populace. The scheme has recorded several challenges; as a result, policymakers and donor agencies are reconsidering the current NHIS model and are thinking of crafting a better alternate and sustainable financial model for the NHIS. This study seeks to propose a multifactor authentication framework for the national health insurance scheme in Ghana using soft-computing machine learning techniques to minimize the current challenges. It was observed that the proposed system used $1.02 \mathrm{sec}$ to vet 25 claim forms, while the human professional used $120 \mathrm{sec}$ for a single document. The accuracy (91.50\%) and F1 (88.52) score measure obtained shows a higher rate of the vetting process by the proposed system.
\end{abstract}

Keywords: Natural Language Programming, Multifactor, Authentication, National Health Insurance Scheme, Healthcare, Cash and Carry

\section{Introduction}

Access to eminence health service has been an issue globally. A study by the World Health Organisation (WHO) revealed that approximately four hundred (400) million people worldwide do not have access to affordable health service (Dalinjong et al., 2017). Besides, as a result of paying for health service by people living in under-develop and developing countries, $6 \%$ of people in these countries are in extreme poverty (Dalinjong et al., 2017). On the other hand, the essential objective of every health system is universal health coverage. Where every individual have access to good and quality health care services when the need arises without any financial barriers (Dalinjong et al., 2017; Parmar et al., 2014; Williams et al., 2017), quality healthcare, according to (Alhassan et al., 2015) can be cluster into perceived and technical, where perceived centres on experiences, opinions and contentment with the service delivery processes.

In contrast, technically refers to structured-processes and professionally well-defined practices and etiquettes of care (Alhassan et al., 2015). However, quality Healthcare Financing (HCF) has become a hot issue of discussion globally. The HCF systems are typically designed to incorporate both informal and formal sectors, cities and rural settlements and all types of income earners. As such, it has become a challenge for its managers to maintain the system with adequate cash flow effectively. As a result, several developing and developed countries keep researching for ways and opportunities to provide adequate funding for their health care system (Addae-Korankye, 2013; Aniah, 2016).

Healthcare financing can be categorized into four (4) main models, namely, the Beveridge Model (BeM), the National Health Insurance Model (NHIM), the Bismarck Model (BiM) and the Out-of-Pocket ("cash and carry") Model (OPM) (Chung, 2017). In a similar study, the authors grouped HCF models in five (5), these include Taxation (TM); Voluntary and Private Insurance (VPI); Social Health Insurance (SHI); Outof-Pocket (OPM) or cash-and-carry; and donations (Addae-Korankye, 2013). These models are believed to have individual policy separations. However, in implementation, most countries combine two or more, though their healthcare system is uniform for all citizens. These differences are effective at distinguishing schools of believed on healthcare policy; nonetheless, the policies for each country should be examined when defining potential improvements (Chung, 2017). Studies 
revealed that choosing the right model from the models mentioned above leads to a sustainable source of healthcare financing and this has become a subject of discussion among stakeholders (Addae-Korankye, 2013).

Public Health Insurance (PHI) in African is not conventional as compared with other continents such as Europe, America and Asia. However, Ghana is among the few countries in African that have passed a bill, allocated substantial proceeds and begun implementation of a PHI program everyone in the country (Schieber et al., 2012). The National Health Insurance Scheme (NHIS) introduced in Ghana within 2003-2005 (i.e., legislative started in 2003-2004 and its implementation in 2005) was aimed at providing affordable health care for the entire population of Ghana by replacing the then existed cash and carry system (Adisah-Atta, 2017; Alhassan et al., 2015; Aniah, 2016; Nsiah-Boateng et al., 2016; Schieber et al., 2012). The NHIS of Ghana within its first four years of introduction recorded a profit and since then has been facing several deficit challenges. As a result of increasing membership enrollment, hospital attendance and healthcare cost, in-built problems such as high claims cost, fraud, poor service quality and excessive utilization (Addae-Korankye, 2013; Adisah-Atta, 2017; Aniah, 2016; Nsiah-Boateng et al., 2016; 2017; Quaye et al., 2015; Schieber et al., 2012; Williams et al., 2017).

As a means to remove the challenges mentioned above, policymakers (Ministry of Health and Ministry of Finance) and donor agencies are faced with reconsidering how the health sector can be financed and sustained (Adisah-Atta, 2017; Aniah, 2016; Ministry of Health, 2015; Schieber et al., 2012). The need for a new and innovative HCF model is sought globally to ensure that the quality of primary healthcare is made available for everyone (Addae-Korankye, 2013; Lustig, 2016). Furthermore, at an affordable fee or virtually free without bias, which again will maximize benefits for the medical doctor and the patient (Addae-Korankye, 2013; Lustig, 2016).

Therefore, in line with the above discussions, the current study seeks to:

1. Identify the challenges facing the current financial framework of the NHIS in Ghana (NHISGh)

2. We proposed a novel multifactor authentication framework, combined with machine learning techniques to enhance the existing NHISGh for a sustainable and robust payment system

The following research questions were formulated to guide this study:

1. What are the challenges facing the current NHISGh model?
2. How do we incorporate secure authentication and machine learning techniques into the existing NHISGh framework to elevates the problems in (1)?

We hope that the proposed framework would offer a robust and secure authentication enhancement to the existing public HCF system of the HNIS in Ghana and beyond.

The remaining sections of this paper are categorized as follows. Section 2 presents a discussion on available Healthcare Financial (HCF) models, the development of $\mathrm{HCF}$ in Ghana and the challenges facing the current HCF in Ghana. Section 3 presents the methodologies adopted for improving the authentication framework of the current HCF in Ghana for a sustainable and robust payment system. In section 4 , we present the results and discussion of the study. Finally, section 5 presents the conclusions and recommendation of this study.

\section{Literature Review}

This section presents a review of the development and approaches in HF locally and abroad. The types of healthcare funding tools; development in Ghana healthcare financing and challenges faced by the system.

\section{Funding Tools}

According to literature, there are several funding tools and methods available for healthcare financing. As a result, some developed countries combine two or more of these methods to formulate a single model for their healthcare system. Table 1 present a summary of the healthcare financing models and countries using them. The subsequent section describes these tools and methods in brief.

\section{The Bismarck Model (BiM): Social Health Insurance}

Otto von Bismarck introduced the BiM in the 19th century. This model focus on a more decentralized approach to the healthcare financing system, where employees and employers contribute money to keep the system running. Compulsory payroll deductions of employees provide them access to "sickness funds." Besides, private insurance plans shield all employed personnel, irrespective of pre-existing circumstances (Addae-Korankye, 2013; Chung, 2017; Kulesher and Forrestal, 2014). However, there are variations within this model, but the most common comprises amount to contributed by employees and employers. The differences among BiM implementation in various countries are subject to the collection agent (insurers) and their functions. For example, in Korea and France, there is a single collection agent while countries such as the Czech Republic and Germany have multiple competing collectors. 
Nonetheless, irrespective to the number of insurers, the government exclusive controls the prices. Thus, allowing the government of the day to implements a comparable amount of control over prices for healthcare services in the BiM. The BiM is noted for its transparency in the revenue collection, making it acceptable to the public. Again, theoretically, the BiM provide a cover of the accumulated funds from political intrusion, since budgetary and spending pronouncements are in the hands of independent bodies (Addae-Korankye, 2013). However, the initial plan of BiM was not for universal health coverage. Thus, the resources of BiM was focused on financial contributors. However, with a shift from healthcare as a benefit to employed citizens to quality healthcare for all citizens, the BiM faces several concerns. For example, how to care for those who cannot work or those who cannot afford contributions (Chung, 2017). Hence, (Nsiah-Boateng et al., 2019) argues that if $\mathrm{BiM}$ is well implemented can decrease out-of-pocket payments and accompanying cataclysmic effects on citizens.

\section{The Beveridge Model (BeM): Single-Payer NHS}

The BeM is a centralized healthcare financing system developed in 1948 by Sir William Beveridge and first established in the UK. Currently, the BeM spans across Northern Europe to the uttermost part of the world (Chung, 2017). Subsequently, in the BeM, the government serves as the only contributor (single-payer), using income taxes, which eliminates any competition in the market and hence keeps the price low. The BeM health financing permits free healthcare for all at health centres when in operation. Therefore, patients access the health facility needs not to pay anything (i.e., no "cash and carry") due to their contribution through taxes (Addae-Korankye, 2013; Chung, 2017; Kulesher and Forrestal, 2014). Countries such as Denmark, New Zealand, Bulgaria, Finland, Sweden, the United Kingdom, Cuba, Spain and Norway use the BeM for healthcare financing. Under the BeM, a vast majority of health staff comprises of government employees. The pivot of the BeM is health as a human right. Thus, universal coverage is assured by the government and any person who is a legal resident has equal access to care (Chung, 2017).

On the other hand, a significant challenge raised in literature against the $\mathrm{BeM}$ is the propensity toward elongated waiting lists. Due to equal access to system utilization and overuse of the system, mighty lead to increase in cost. However, to some studies, more money is spent on the $\mathrm{BiM}$ in an attempt to cover the uninsured (Chung, 2017; Engelhard, 2015). Furthermore, a critical concern of the BeM is the response of the movement to the crisis. In situations such as national emergencies such as health crisis or war, the funding for the BeM mighty fails (Addae-Korankye, 2013; Chung, 2017). Due to public revenue reduction, they are aggravating the financial liability integral in a massive inflow of patients (Addae-Korankye, 2013; Chung, 2017).

\section{The Out-of-Pocket Model (OPM): Market-driven Health Care}

Another commonly known healthcare financing model is the Out-of-Pocket Model (OPM), also known as "cash and carry" (Addae-Korankye, 2013; Aniah, 2016; Chung, 2017; Kulesher and Forrestal, 2014; Lustig, 2016). In this model, patients are required to make a direct payment for healthcare services at the point of delivery. As a result, the underprivileged are not capable of accessing quality healthcare without enough money. Unfortunately, OPM is common among most developing countries since only the affluent countries have dynamic healthcare systems. Differences in prosperity lead to inequalities in health products in these areas (Chung, 2017).

According to (Addae-Korankye, 2013), health financing based on OPM is in three (3) forms, thus: (i) The patients access the healthcare services pay for the service not covered by the insurance. (ii) Paying for partially covered services by the insurance package and (iii) paying for entirely founded healthcare services from mutual proceeds, however, requires extra payments. Advocates of this third form of OPM argues that it serves as additional means of raising extra funds to support the OPM. However, OPM is seen to be suitable in regions where there is a non-functioning universal healthcare system. In addition to insufficient resources of the government to meet quality healthcare system requirements. Moreover, it can lead to reducing cohesion between people in good physical shape and not, because well-off people no longer support for underprivileged people who cannot afford healthcare (Addae-Korankye, 2013; Jehu-Appiah et al., 2011).

\section{The National Health Insurance (NHI) Model: Single-Payer NHI}

The NHI model integrates aspects of both the BiM and BeM and are very common among low and middleincome countries (Addae-Korankye, 2013; Chung, 2017; Nsiah-Boateng et al., 2016). Like the BeM, the government stands as the sole financier for healthcare processes and like the BiM, providers are private. The NHI model does not deny claims or make a profit. Serval countries practising the BeM of health financing seeks to incorporate BiM characteristics or vice versa; this has led to the hybridization of models in countries such as Germany and Hungary (Chung, 2017). Challenges associated with the NHI models are (i) no evidence to assess if grants increase effects net expenditure on healthcare services. (ii) Sustainability of 
healthcare financing in the long term cannot over depend on donor assistance as the priority of donor partners are changing with time.

Despite the advantages and disadvantages associated with each HCF model, the concerns faced by individual countries are not similar when it comes to creating a healthcare delivery system. Similarly, no healthcare financing model is free from problems and no two systems are identical. Thus, a model that fits perfectly for country "A" might not be entirely transferrable for country "B", because of dissimilar health importance, beliefs and worries. Notwithstanding, the complications associated with the implementation of these healthcare financing models, it is essential for the NHIS in Ghana (NHISGh) to implement a financial model that operates in fairness and just for all the citizens and elevates the problems associated currently model been used by the NHISGh.

\section{Development of HCF in Ghana}

Healthcare financing in Ghana has undergone several changes right before and after independence. HCF before the independence of Ghana was based on the OP and right after independence, $\mathrm{HCF}$ changed to the $\mathrm{BeM}$ (solely tax based), where quality healthcare was made free for all citizens. On the other hand, the BeM introduce after independence did not last for long, mainly due to the competing financial needs from other sectors of the economy (Addae-Korankye, 2013; Aniah, 2016). As a result, different healthcare financing was introduced within the $70 \mathrm{~s}$, one of which is known as user-fee. The user-fee became necessary as a mean for the then Busia's government to decrease its financial expenditure and again make available coverage for exempting citizens with specific severe illnesses. The user-fee model did not last for long due to the change in government. The healthcare financing kept changing from funded by the national health system (free healthcare for all) to "cash and carry". However, in the 1980s, the Hospital Fees Act 387 brought in the nationwide fee-for-service. With this Act, citizens were expected to pay a token for healthcare delivery. Table 2 presents a summary of the sequential development of $\mathrm{HCF}$ changes in Ghana.

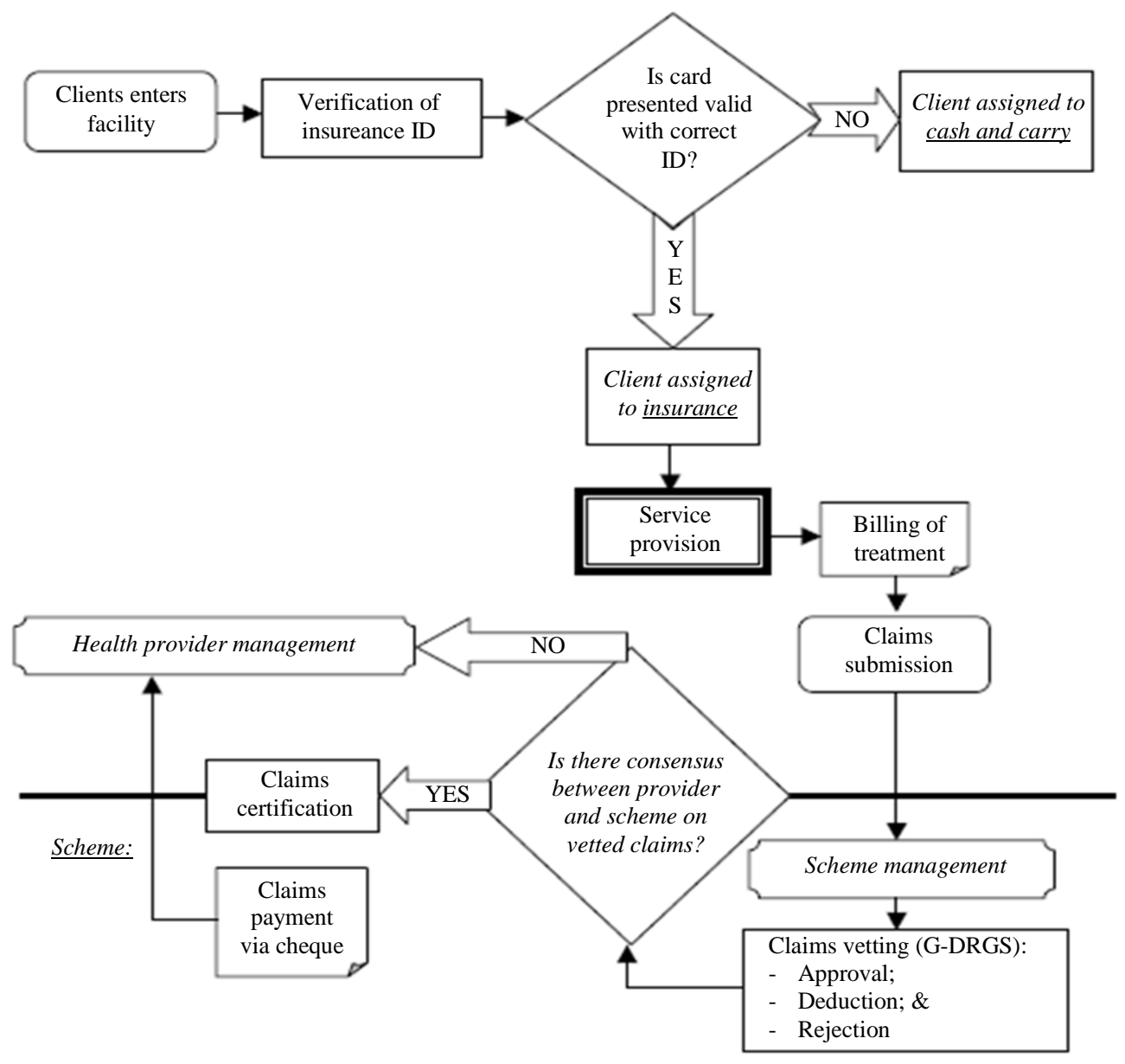

Fig. 1: Flowchart on NHISGh current claims process (Source (Sodzi-Tettey et al., 2012)) 
Table 1: A summary of healthcare financing models and countries using them

\begin{tabular}{ll}
\hline NHS model & Example countries \\
\hline BiM & Czech Republic, Switzerland, Frances, Belgium, Germany, Romania, Croatia, Estonia, Hungary and Slovakia \\
& Japan, Austria, Lithuania and Switzerland \\
BeM & Denmark, New Zealand, Bulgaria, Finland, Sweden, the United Kingdom, Cuba, Spain and Norway \\
OPM & India, South America, China, Africa, \\
NHI model & Canada, Taiwan, South Korea \\
\hline
\end{tabular}

Table 2: Sequential development of HCF in Ghana (source: (Adisah-Atta, 2017))

\begin{tabular}{|c|c|c|c|c|c|}
\hline Year & Event & Rationale & Features & Sources of financing & Results \\
\hline 1957 & $\begin{array}{l}\text { Creation of a National } \\
\text { Health Service (NHS) } \\
\text { carved after the British } \\
\text { scheme }\end{array}$ & $\begin{array}{l}\text {-Motivated by initial } \\
\text { economic performance, } \\
\text { natural-resources and } \\
\text { a robust export-base }\end{array}$ & $\begin{array}{l}\text {-Free healthcare for all } \\
\text {-Healthcare provision } \\
\text { over a network of state- } \\
\text { owned facility }\end{array}$ & Common proceeds & $\begin{array}{l}\text { unsustainable with the drop } \\
\text { in economic-performance, } \\
\text { the scheme proved to be } \\
\text { too expensive }\end{array}$ \\
\hline 1985 & $\begin{array}{l}\text { Co-payments } \\
\text { introduced }\end{array}$ & $\begin{array}{l}\text { Co-payments for } \\
\text { services }\end{array}$ & $\begin{array}{l}\text { Co-payments for services } \\
\text {-Healthcare delivery via } \\
\text { a network of publicly } \\
\text { government-owned } \\
\text { facilities }\end{array}$ & $\begin{array}{l}\text { General revenue and } \\
\text { user fees }\end{array}$ & $\begin{array}{l}\text { OPM user charges from } \\
\text { partial-to-full recovery }\end{array}$ \\
\hline 1992 & $\begin{array}{l}\text { Cash-and-carry } \\
\text { system instituted }\end{array}$ & $\begin{array}{l}\text {-To increase funds for } \\
\text { providers -To make fee } \\
\text { recovery legal -to limit } \\
\text { needless use }\end{array}$ & $\begin{array}{l}\text { Full-cost retrieval for } \\
\text { drugs -Reduced fees for } \\
\text { children and primary } \\
\text { care facilities }\end{array}$ & $\begin{array}{l}\text { General revenue and } \\
\text { user fees }\end{array}$ & $\begin{array}{l}\text { Outpatient visits dropped } \\
\text { by } 66 \%\end{array}$ \\
\hline $\begin{array}{l}\text { The early } \\
1990 \text { s }\end{array}$ & $\begin{array}{l}\text { Voluntary mutual } \\
\text { health insurance } \\
\text { organization movement }\end{array}$ & $\begin{array}{l}\text {-Heavy cash-and-carry } \\
\text {-Lack of social } \\
\text { protection mechanisms } \\
\text {-Lack of government } \\
\text { oversight of the } \\
\text { informal sector }\end{array}$ & $\begin{array}{l}\text {-Subsidization of the } \\
\text { vulnerable by the better } \\
\text { off } \\
\text {-Social protection against } \\
\text { the impoverishing } \\
\text { cost of illness }\end{array}$ & $\begin{array}{l}\text { Donors such as the } \\
\text { DANIDA and USAID } \\
\text {-Community }\end{array}$ & $\begin{array}{l}\text {-Reduced gap between } \\
\text { those covered and those } \\
\text { not covered } \\
\text {-Paved the way for the } \\
\text { spread of MHOs }\end{array}$ \\
\hline $\begin{array}{l}\text { The early } \\
2000 \text { s }\end{array}$ & Profusion of MHOs & $\begin{array}{l}\text { The trend in other } \\
\text { African nations } \\
\text {-The success of initial } \\
\text { MHOs in Ghana } \\
\text {-Encouragement by } \\
\text { the ministry of health }\end{array}$ & $\begin{array}{l}\text {-Stretched among } 67 \\
\text { district out of } 138 \text { in } \\
10 \text { regions } \\
\text {-Diverse in management } \\
\text { styles and remunerations } \\
\text {-Centred on the } \\
\text { constituency or the } \\
\text { inhabitant's occupation } \\
\text { or religion or gender }\end{array}$ & $\begin{array}{l}\text { Donors such as the } \\
\text { DANIDA and USAID } \\
\text {-Community }\end{array}$ & $\begin{array}{l}\text {-Financial protection and } \\
\text { health services access for } \\
\text { poor } \\
\text {-Model for covering more } \\
\text { significant parts of the } \\
\text { population }\end{array}$ \\
\hline 2003 & $\begin{array}{l}\text { National mandatory } \\
\text { healthcare-insurance } \\
\text { reform }\end{array}$ & $\begin{array}{l}\text { the relative achievement } \\
\text { of the MHOs } \\
\text {-Agenda of the ruling } \\
\text { government (election } \\
\text { platform) }\end{array}$ & $\begin{array}{l}\text { Abolish cash and carry } \\
\text {-introduced mandatory } \\
\text { health insurance } \\
\text {-expend coverage } \\
\text { through MHOs in all } \\
\text { district }\end{array}$ & $\begin{array}{l}\text { National Health } \\
\text { Insurance Levy (NHIL) } \\
2.5 \% \text { VAT of SSNT } \\
\text { state budget transfer } \\
\text {-Return on the } \\
\text { investment made by the } \\
\text { National Insurance } \\
\text { Council } \\
\text {-Voluntary contributions }\end{array}$ & $\begin{array}{l}\text { National Health Insurance } \\
\text { Council set up } \\
\text {-Interim administration } \\
\text { arrangements introduced } \\
\text {-move toward } 90 \text { districts } \\
\text { mutual health schemes }\end{array}$ \\
\hline
\end{tabular}

SSNIT $=$ Social Security and National Insurance Trust. Formal sector workers pay 5\% of their wages to the SSNIT and their firms pay $12.5 \%$

\section{The Payment Model of NHIS in Ghana}

Figure 1 shows the structure of the current claim process of the NHIS in Ghana. The clients visit a hospital and present his/her insurance ID card to the staff of the healthcare provider. The ID is checked for validity; when valid, the client is assigned to the NHIS and if not, the client is assigned to cash and carry payment system. Claims are submitted either manually or electronically to the NHIS managers. Manual verification of all forms submitted takes place by the official of the NHIS and if everything is correct payment is initiated. This manual verification process consumes much time and opens the door for human perpetuated frauds (Addae-Korankye, 2013; Alhassan et al., 2016;
Aniah, 2016; NHIA, 2010; Nsiah-Boateng et al., 2016; Schieber et al., 2012).

\section{Challenges Faced by the NHIS in Ghana}

The search for a better healthcare financing model in Ghana resulted in Act 650 and (LI 1809) in 2003, which established the NHIS in Ghana (NHISGh). The NHISGh was aimed at eradicating every financial barrier generated by the previous healthcare reforms (Adisah-Atta, 2017; Alhassan et al., 2015; Aniah, 2016; Nsiah-Boateng et al., 2016; Schieber et al., 2012). The NHISGh sought to provide quality and affordable healthcare to Ghanaians. The source of funding the new NHISGh was from $2.5 \%$ VAT impose on services and 
certain goods, $2.5 \%$ of employees SSNIT contribution, the consolidated fund, grants, donations, gifts and charitable contributions. The accrued profit on investment by the National Health Insurance Council (NHIC) and from step-up premium contributions by individuals in the informal sector of $\phi 72,000-\phi 480,000$ (GHф7.2-GHф48.0).

According to (Dalinjong et al., 2017) cited in (Adisah-Atta, 2017), the lack of clarity and complexities in this step-up premium has resulted in the present flatrate premiums contributions, with individuals typically paying the bottommost premium of $\mathrm{GH} \phi 7.2$ and this makes it deteriorating. However, much success was recorded in the early year of its implementation because of donor supports and grants from the international organization (Adisah-Atta, 2017; Alhassan et al., 2015; Aniah, 2016; Nsiah-Boateng et al., 2016; Schieber et al., 2012). Currently, the scheme receives its funds in three ways $47 \%$ from both direct and indirect tax, $48 \%$ outof-pocket payment and $4.3 \%$ from supplementary sources (Adisah-Atta, 2017). There are still financial issues and other problems facing the scheme, below are a few of these issues:

1. Means and process for proof-of-identity of the poor unto NHISGh have shown incompetent. The first test for identifying the poor is considered to be inflexible within the local contexts of the word "poor person", which has led to the reduced enrolment of the indigents (Addae-Korankye, 2013; Alhassan et al., 2016; Andoh-Adjei et al., 2018; Dalinjong et al., 2017)

2. Premiums unaffordability alleged poor quality of healthcare, awareness of an insufficient benefit package due to some treatment and drugs for some illnesses not being covered, lack of trust in NHISGh officials, a complicated registration process, delay in the issue of membership cards and long queues before one is attended to at healthcare centres (Alhassan et al., 2015; 2016; Andoh-Adjei et al., 2018; Aniah, 2016; Parmar et al., 2014; Williams et al., 2017)

3. Though the NHISGh is a social protection guiding principle and a fund into which individuals contribute, end-user voice on its processes is minimal (Addae-Korankye, 2013; Alhassan et al., 2016; Andoh-Adjei et al., 2018). Thus, limited community participation

4. Also, there exist matters of the feeble system and human aptitude for claims management, audit and fraud control (Addae-Korankye, 2013; Alhassan et al., 2016; Aniah, 2016; NHIA, 2010; Nsiah-Boateng et al., 2016; Schieber et al., 2012). This creates setbacks in schemes agreement on claims, opening the doors for fraudulent and wrong claims, delay in payment of claims which can cause providers agitation. All these lead to the undermining of the quality of healthcare service delivery to clients

Any technique that seeks to eliminate or minimize these identified challenges will lead to the sustainment of the NHISGh. Hence, this study proposes a multifactor authentication framework based on Artificial Intelligence (AI) and Data Analytics (DA) techniques to enhance the existing NHISGh financial model. The contributions of this study to the current NHISGh HCF framework are as followed:

1. An embedded fingerprint recognition system for multifactor authentication of cardholders

2. An SMS alert to cardholders when a claim is submitted in their names

3. Automatic validation and classification of submitted claims by healthcare providers in the NHISGh using Natural Language Programming (NLP) techniques

\section{Methodology}

This section presents the materials and methods adopted for the study.

\section{Study Design}

A mixed-method design was adopted for this study; primary and secondary data sources were employed using random sampling. Figure 2 presents the flowchart of the proposed multifactor authentication framework for efficient and secured NHIS payments structure for the national health insurance authority in Ghana. We put forward a dual authentication of NHIS holders by what they have (insurance ID) and whom they are (fingerprint) before assigning them to the NHIS services at the health centre otherwise to cash and carry system.

The patient is then provided with the services covered by the NHIS. The healthcare centre prepares the bill and submits it to the fund managers. Immediately the fund managers received the bill an SMS is sent to the patients alerting them of their visit to the concerned healthcare at the said dates. The claims are sent to the proposed Natural Language Processing (NLP) unit. At this unit, we applied text mining and analytics algorithm on each submitted claim. The submitted claims are presented transformed into an array string and each element is treated separately in a loop through the NLP processes. The NLP processes validated of the healthcare provider status; validated of the patient details, validate the treatment cost and other constraints when all checks are correct the system check if patients have sent any disagreement with their visit to the healthcare. When there is no such report claims a certified and sent for 
approval and onwards payment, while a message is sent to the healthcare provider concerned.

On the other hand, when there is any report from the patients, the claims processing is halted for further investigation.

The NLP process involved three (3) phases. At the first phase, each claim is passed through a pre-processing data stage, which involves:

(i). Tokenisation where the claims sentences are converted to words

(ii). Removing of needless tags and punctuations;

(iii). Get rid of stop words (such as" is"," the" and more.) that do not have specific semantic and

(iv). Stemming, reducing words to root by removing accent employing dropping needless characters, generally a suffix

The Natural Language ToolKit (NLTK) was used for all stages of the data pre-processing. Second phase: Feature-extraction the Bag-Of-Words (BOW) and the
Term Frequency-Inverse Document-Frequency (TF-IDF) techniques were adopted for this study.

Team Frequency $(T F)$

$=\frac{\text { Number of time }(t) \text { appears in a document }}{\text { Number of terms in the document }}$

Inverse Document Frequency $(I D F)=\log \left(\frac{N}{n}\right)$

where $N=$ entire documents and $n$ is the number of documents, a term $t$ has appeared in.

$$
\text { We calculate }(T F-I D F) \text { value of atermas }(T F \times I D F)
$$

The third phase involves choosing machine learning algorithms; the Support Vector Machines (SVM) was adopted using the Scikit-learn library and Python, where the SVM is already coded.

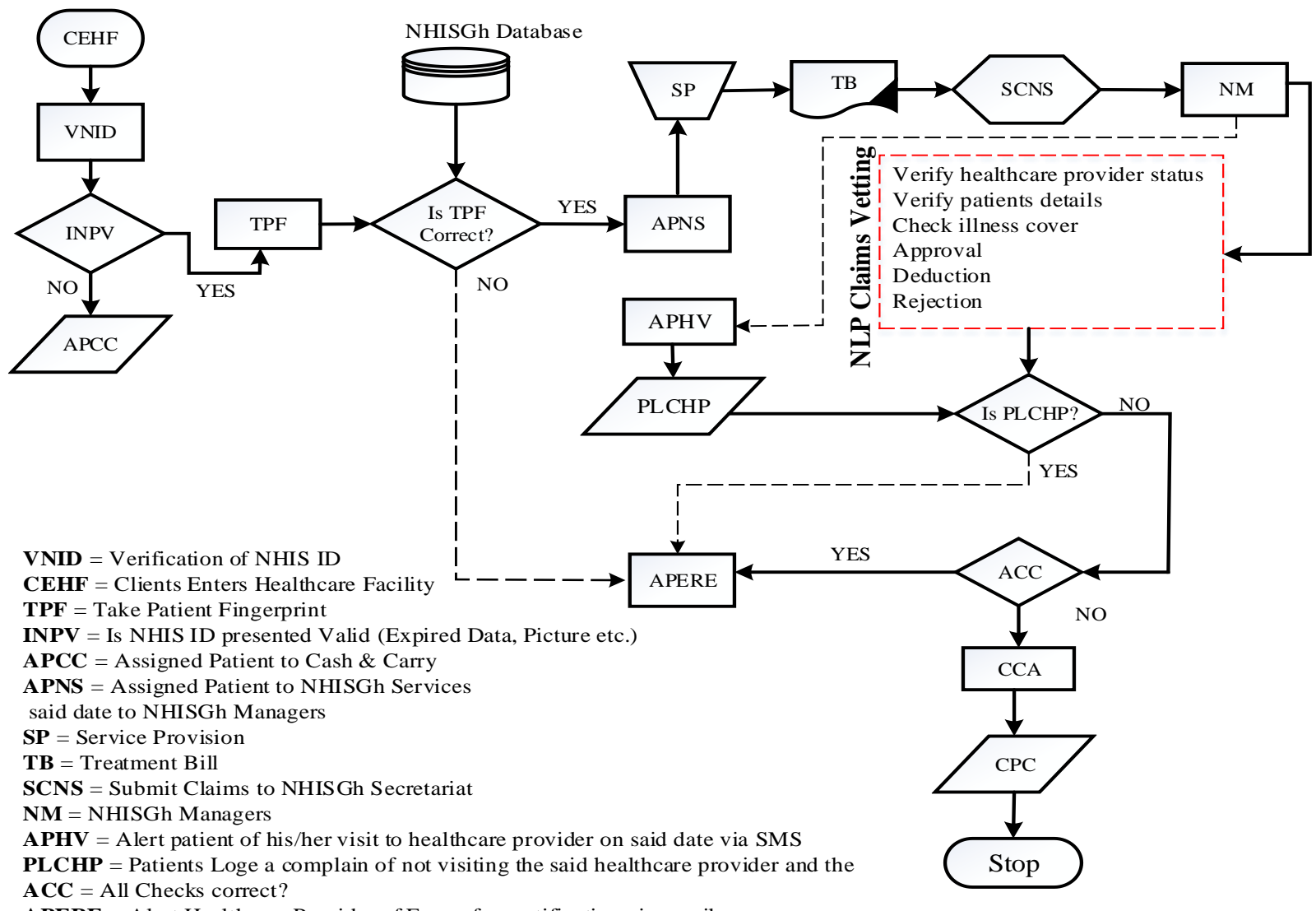

APERE = Alert Healthcare Provider of Errors for rectification via email

CCA = Claims certification and approval by NM

$\mathbf{C P C}=$ Claims Payment via Cheque

Fig. 2: Flowchart for proposed multifactor authentication system for NHIS payments 


\section{Results and Discussion}

The experimental setup and results of the study are discussed in this section. Twenty-five (25) NHISGh claims forms from two health centres in the Dorma district, Bono Region were used to analyze the proposed framework. 10-fold cross-validation was used in this study due to the size of our data size. The experiments were centred on the computational time of the system, as claims processing time was one of the challenges identified in the literature. The experiments were carried on a Samsung laptop, with Windows 10, 64 bit, 6GB RAM and Intel (R) Core TM i5-2410M @ $2.3 \mathrm{GHz}$.

Results

A secure authentication mechanism was introduced with the help of biometric verification into the proposed enhancement of the existing NHISGh claims processes. Thus, a fingerprint verifier at healthcare centres to doublecheck the identity of cardholders. Again, an SMS notification to cardholders whenever a claim is presented with their details. By this, the cardholder can report to the NHISGh managers if there is any fraud in the said claims.

\section{Computation Time}

The twenty-five (25) forms were grouped into [1, $5,10,15,20$ and 25]. Each group were given in batches to the proposed system and a human professional to vet the forms. Table 3 shows the comparison of vetting times of claims forms between the proposed system and manual process. It was observed that the proposed system used $1.02 \mathrm{sec}$ to vet all 25 forms while the human professional used $120 \mathrm{sec}$ for a single document. Sodzi-Tettey et al. (2012) pointed out in their study that $98 \%$ of the current NHISGh claims are normally processed within 30 days because of computerization (Sodzi-Tettey et al., 2012). Furthermore, (Sodzi-Tettey et al., 2012) reported that the software currently used by the NHISGh could process over 40, 000 claims in one day (Sodzi-Tettey et al., 2012). These results show that the proposed system can process 40,000 claims within 400-600 sec, an extra computational reduction in claims forms processing.

Table 3: Comparison of vetting claims time between the proposed system and manual

\begin{tabular}{lll}
\hline $\begin{array}{l}\text { No. of } \\
\text { documents }\end{array}$ & $\begin{array}{l}\text { Proposed } \\
\text { system (seconds) }\end{array}$ & $\begin{array}{l}\text { Manual } \\
\text { vetting (seconds) }\end{array}$ \\
\hline 1 & 0.010 & 120 \\
5 & 0.070 & 600 \\
10 & 0.099 & 1200 \\
15 & 0.253 & 1800 \\
20 & 0.912 & 2400 \\
25 & 1.020 & 3000 \\
\hline
\end{tabular}

Table 4: Vetting performance: 10 -fold CV

\begin{tabular}{lll}
\hline RMSE & F1 & Accuracy \\
\hline 0.002 & $88.52 \pm 1$ & $91.50 \pm 1.5$
\end{tabular}

\section{Accuracy and Error Metric}

The details of the performance of the proposed framework are as shown in Table 4. The results show the Root Means Square Error (RMSE), Accuracy and F1. The results reveal high accuracy measure with less computational (vetting) time.

\section{Discussion}

The claims processing time and potential human fraud were among the issues identified as the key challenges facing the existing payment structure of the NHISGh. To remedy these issues, we proposed multifactor authentication and NLP techniques. For twenty-five (25) claims forms the proposed system used $1.02 \mathrm{sec}$ and compared to $3000 \mathrm{sec}$ by human professional. The results imply that when the NHISGh managers absorb the proposed system, the challenges concerning processing speed is going to reduce by $12,000 \%$ of the current vetting time. Again, the results show that the proposed system is practicable for even large data set, with less time difficulty. The speed of processing implies that 40,000 claims can be processed with a maximum of $600 \mathrm{sec}$. The processing speed is dependent on the computer used, which means the processing speed can be increased further with a high-speed computational machine. The accuracy (91.50\%) and F1 (88.52) score measure obtained shows a higher rate of the vetting process by the proposed system. The study outcome shows how the proposed system is feasible for big-data processing with little processing times.

\section{Conclusion and Future Research}

Several studies have been carried out on the National Health Insurance Scheme in Ghana (NHISGh). However, a high percentage of these studies emphasize identifying the challenges and opportunities within the NHISGh. This study, on the other hand, sought to summaries the identified challenges in the literature and proposed a secured mechanism to eliminate them. The study proposed a multifactor authentication and machine learning algorithms to enhance the existing NHISGh claims structure to provide a sustainable financing system for the NHISGh.

The experimental results of the study show a high reduction in computational time as compared with the existing system and a two-way authentication system to reduce and potential human frauds in the existing system. All the same, the study was limited, thus, lack of access to quality and reliable information, particularly from healthcare centres, because of their code of ethics on clients chat and privacy.

Notwithstanding, our study shows a significant reduction in computational cost and a well-secured 
claimant authentication, but accuracy improvement is trivial. Future work, need to devise methods to improve accuracy and incorporate additional machine learning algorithms to cluster claims for further analysis.

\section{Acknowledgement}

We acknowledge all who contributed in a way or the other to bring this research into the lamplight.

\section{Author's Contributions}

All authors equally contributed to this work.

\section{Ethics}

This article is original and contains unpublished material. The corresponding author confirms that all of the other authors have read and approved the manuscript and there are no ethical issues involved.

\section{References}

Addae-Korankye, A. (2013). Challenges of financing health care in Ghana: the case of national health insurance scheme (NHIS). International Journal of Asian Social Science, 3(2), 511-522.

Adisah-Atta, I. (2017). Financing health care in Ghana: are Ghanaians willing to pay higher taxes for better health care? Findings from Afrobarometer. Social Sciences, 6(3), 90.

Alhassan, R. K., Duku, S. O., Janssens, W., NketiahAmponsah, E., Spieker, N., van Ostenberg, P., ... \& Rinke de Wit, T. F. (2015). Comparison of perceived and technical healthcare quality in primary health facilities: implications for a sustainable National Health Insurance Scheme in Ghana. PloS one, 10(10), e0140109.

Alhassan, R. K., Nketiah-Amponsah, E., \& Arhinful, D. K. (2016). A review of the National Health Insurance Scheme in Ghana: what are the sustainability threats and prospects? PloS one, 11(11), e0165151.

Andoh-Adjei, F. X., van der Wal, R., Nsiah-Boateng, E., Asante, F. A., van der Velden, K., \& Spaan, E. (2018). Does a provider payment method affect membership retention in a health insurance scheme? A mixed method study of Ghana's capitation payment for primary care. BMC health services research, 18(1), 52.

Aniah, E. (2016). Prospects and challenges of the national health insurance scheme in Tolon district of Ghana (Doctoral dissertation).

Chung, M. (2017). Health care reform: learning from other major health care systems. Princeton Public Health Review.
Dalinjong, P. A., Welaga, P., Akazili, J., Kwarteng, A., Bangha, M., Oduro, A., ... \& Goudge, J. (2017). The association between health insurance status and utilization of health services in rural Northern Ghana: evidence from the introduction of the National Health Insurance Scheme. Journal of Health, Population and Nutrition, 36(1), 42.

Engelhard, C. L. (2015). Time for an all-payer health system. https://thehill.com/blogs/punditsblog/healthcare/246899-time-for-an-all-payerhealth-system

Jehu-Appiah, C., Aryeetey, G., Spaan, E., De Hoop, T., Agyepong, I., \& Baltussen, R. (2011). Equity aspects of the National Health Insurance Scheme in Ghana: Who is enrolling, who is not and why? Social science \& medicine, 72(2), 157-165.

Kulesher, R., \& Forrestal, E. (2014). International models of health systems financing. Journal of Hospital Administration, 3(4), 127-139.

Lustig, M. C. (2016). An overview of U.S. healthcare financial models in the context of recent and projected economic trends. Journal of Health Care Finance, 43(1), 1-22.

Ministry of Health. (2015). NHIS Funding - Ghana Seeks Sustainable Domestic Revenue Streams. http://www.moh.gov.gh/nhis-funding-ghana-seekssustainable-domestic-revenue-streams/

NHIA. (2010). NHIA Annual Report 2009.

Nsiah-Boateng, E., Ruger, J. P., \& Nonvignon, J. (2019). Is enrolment in the national health insurance scheme in Ghana pro-poor? Evidence from the Ghana Living Standards Survey. BMJ open, 9(7), e029419.

Nsiah-Boateng, E., Aikins, M., Asenso-Boadi, F., \& Andoh-Adjei, F. X. (2016). Value and service quality assessment of the National Health Insurance Scheme in Ghana: evidence from Ashiedu Keteke District. Value in health regional issues, 10, 7-13.

Nsiah-Boateng, E., Asenso-Boadi, F., Dsane-Selby, L. andoh-Adjei, F. X., Otoo, N., Akweongo, P., \& Aikins, M. (2017). Reducing medical claims cost to Ghana's National Health Insurance scheme: a crosssectional comparative assessment of the paper-and electronic-based claims reviews. BMC health services research, 17(1), 115.

Parmar, D., Williams, G., Dkhimi, F., Ndiaye, A., Asante, F. A., Arhinful, D. K., \& Mladovsky, P. (2014). Enrolment of older people in social health protection programs in West Africa-Does social exclusion play a part? Social science $\&$ medicine, 119, 36-44.

Quaye, E. A., Amporful, E. O., Akweongo, P., \& Aikins, M. K. (2015). Analysis of the financial cost of diabetes mellitus in four cocoa clinics of Ghana. Value in health regional issues, 7, 49-53. 
Schieber, G., Cashin, C., Saleh, K., \& Lavado, R. (2012). Health financing in Ghana. The World Bank.

Sodzi-Tettey, S., Aikins, M., Awoonor-Williams, J. K., \& Agyepong, I. A. (2012). Challenges in provider payment under the Ghana National Health Insurance Scheme: a case study of claims management in two districts. Ghana medical journal, 46(4), 189.
Williams, G. A., Parmar, D., Dkhimi, F., Asante, F., Arhinful, D., \& Mladovsky, P. (2017). Equitable access to health insurance for socially excluded children? The case of the National Health Insurance Scheme (NHIS) in Ghana. Social Science \& Medicine, 186, 10-19. 